\title{
Trends in the length of the Southern Ocean sea-ice season, 1979-99
}

\author{
Glaire L. Parkinson \\ Oceans and Ice Branch/Code 971, NASA Goddard Space Flight Center, Greenbelt, MD 20771, U.S.A.
}

\begin{abstract}
Satellite passive-microwave data have been used to calculate and map the length of the sea-ice season throughout the Southern Ocean for each year 1979-99. Mapping the slopes of the lines of linear least-squares fit through the 21 years of resulting season-length data reveals a detailed pattern of trends in the length of the sea-ice season around the Antarctic continent. Specifically, most of the Ross Sea ice cover has, on average over the 21 years, undergone a lengthening of the sea-ice season, whereas most of the Amundsen Sea ice cover and almost the entire Bellingshausen Sea ice cover have undergone a shortening of the sea-ice season. Results for the Weddell Sea are mixed, with the northwestern portion of the sea having experienced a shortening of the sea-ice season but a substantial area in the south-central portion of the sea having experienced a lengthening of the ice season. Overall, the area of the Southern Ocean experiencing a lengthening of the sea-ice season by at least 1 day per year over the period 1979-99 is $5.6 \times 10^{6} \mathrm{~km}^{2}$, whereas the area experiencing a shortening of the sea-ice season by at least 1 day per year is $46 \%$ less than that, at $3.0 \times 10^{6} \mathrm{~km}^{2}$.
\end{abstract}

\section{INTRODUCTION}

The Southern Ocean (Fig. 1) sea-ice cover extends over a vast area, approximately $18 \times 10^{6} \mathrm{~km}^{2}$, in the austral winter and experiences an enormous annual decay each spring and summer, with its coverage at the summer minimum typically reduced to $<4 \times 10^{6} \mathrm{~km}^{2}$ (Zwally and others, in press). The ice cover has a substantial impact on regional climate, most prominently by restricting exchanges of heat, mass and momentum between the ocean and the atmosphere and by reflecting most of the solar radiation incident on it. It also has a substantial impact on the biology of the Southern Ocean, for instance housing many species of microorganisms, serving as a platform for penguins, seals and other animals, insulating marine life below the ice from the atmosphere, and reducing light penetration into the ocean. The reader is referred to Bentley (1984), Drewry and others (1993) and Worby and others (1996) for more on the climatological impacts of the ice and to Massom (1988), Drewry and others (1993) and Smith and others (1995) for more on the biological impacts of the ice, including the impacts on primary productivity, phytoplankton blooms, krill and breeding success in seabirds.

Until the 1970s, datasets regarding the Southern Ocean sea-ice cover tended to be sparse both temporally and spatially, due in large part to the vast area, the remoteness from most human habitations and the harshness of the in situ conditions. Fortunately, the ease of obtaining data on the ice cover changed dramatically with the advent of satellite technology. Satellite passive-microwave instrumentation in particular has allowed fairly routine monitoring of the Southern Ocean sea-ice cover since the late 1970s. In fact, the ease with which ice and water can be distinguished in passive-microwave data, due to the sharp contrast in ice and water emissivities at many microwave wavelengths, makes sea-ice coverage now amongst the most readily observed of all climate variables.

This paper takes advantage of satellite passive-microwave datasets over the 21 year period 1979-99 to report on changes in the length of the sea-ice season, defined as the number of days per year with sea-ice coverage, throughout

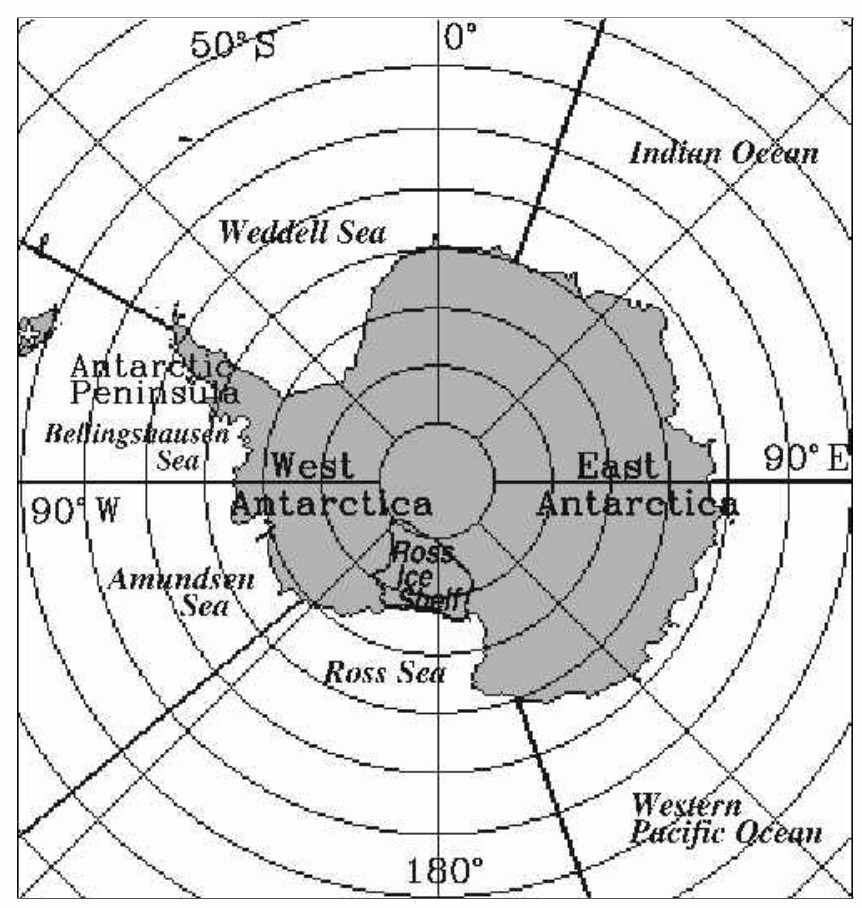

Fig. 1. Location map, including the boundaries of the five sectors into which the Southern Ocean is divided for analysis. The nonland boundaries are along the longitude lines at $20^{\circ} \mathrm{E}, 90^{\circ} \mathrm{E}$, $160^{\circ} \mathrm{E}, 130^{\circ} \mathrm{W}$ and $60^{\circ} \mathrm{W}$. 


\section{a. 1979 (15\% cut-off)}

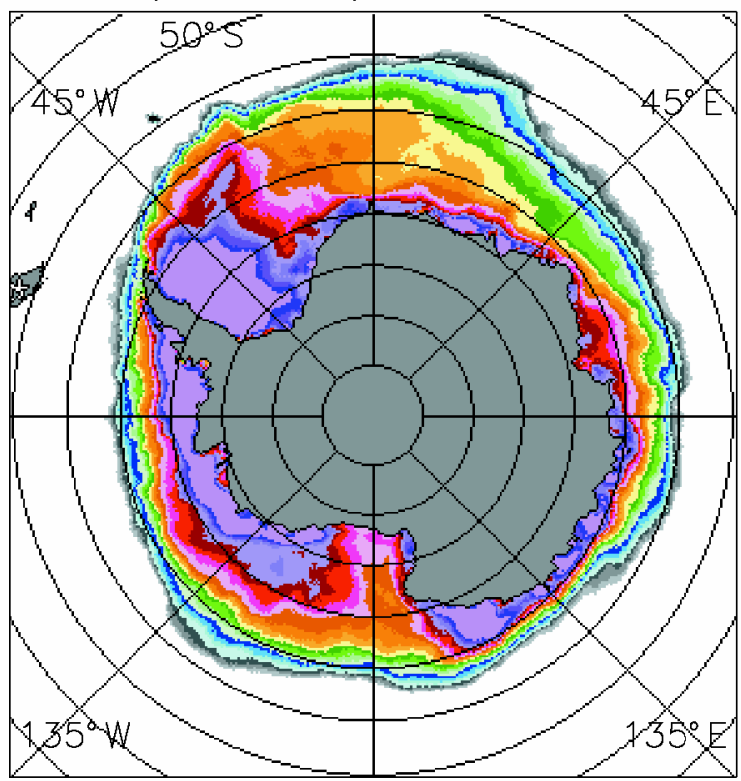

\section{c. $1979-99(15 \%$ cut-off $)$}

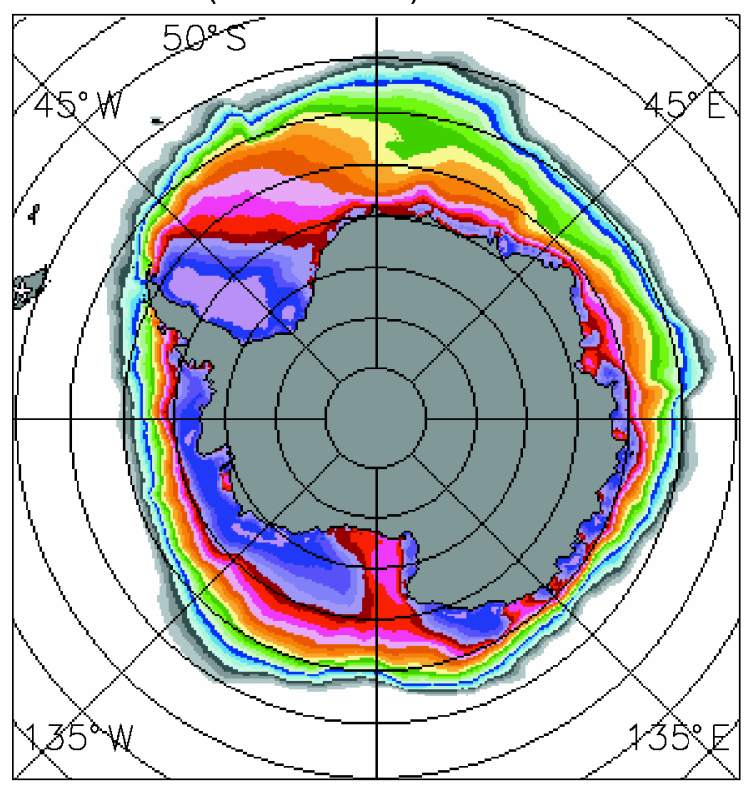

\section{b. 1999 (15\% cut-off)}

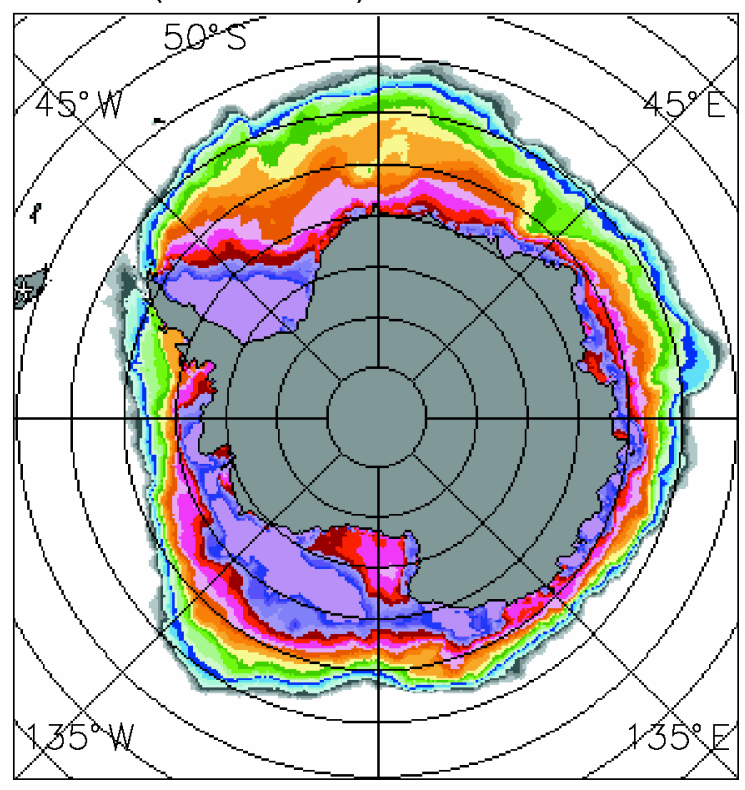

d. $1979-99(50 \%$ cut-off $)$

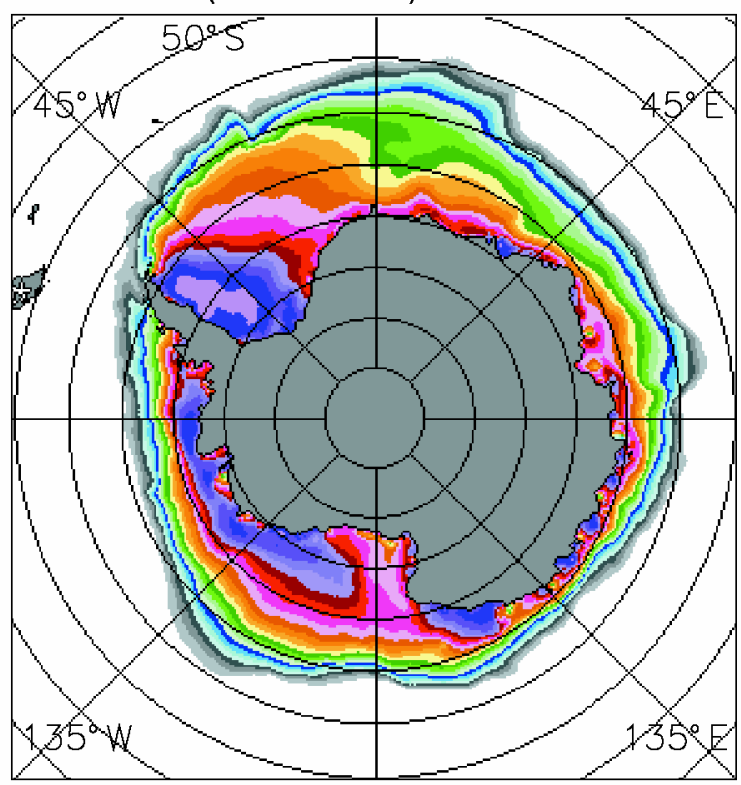

Fig. 2. (a) Length of the sea-ice season for 1979, using a 15\% ice-concentration cut-off, i.e. considering a location to have sea ice if the ice-concentration calculations show at least 15\% ice coverage. (b) Length of the sea-ice season for 1999, using a 15\% iceconcentration cut-off. (c) Average length of the sea-ice season for the 21 years 1979-99, using a 15\% ice-concentration cut-off. (d) Average length of the sea-ice season for the 21 years 1979-99, using a 50\% ice-concentration cut-off.

the Southern Ocean. Changes in the length of the sea-ice season not only affect the regional climate and ecology, in ways alluded to above, but also can serve as indicators of change within the broader climate system. The length of the sea-ice season was first examined and mapped for the Southern Ocean in Parkinson (1994), where results were presented for the 8 year period 1979-86. It has subsequently been examined for the 7 year period 1988-94 by Parkinson (1998) and for the two 8 year periods 1979-86 and 1989-96 by Watkins and Simmonds (2000).

\section{DATA AND METHODOLOGY}

This study uses data from the Nimbus 7 Scanning Multi- channel Microwave Radiometer (SMMR) and the Defense Meteorological Satellite Program (DMSP) Special Sensor Microwave/Imagers (SSM/Is). The SMMR instrument collected data on an every-other-day basis for most of the period 26 October 1978 to 20 August 1987, and the SSM/Is have collected data on a daily basis for most of the period since 9 July 1987. The two datasets have been used by Cavalieri and others (1999) to create a consistent set of sea-ice concentrations (areal percentages of sea ice) using an algorithm commonly termed the NASA Team algorithm. This algorithm is based on the assumption of three surface types (two ice types plus liquid water), polarization and gradient ratios calculated from three channels of the satellite data, and a weather filter. The algorithm is described in detail in Gloersen and others (1992), and the procedures for matching the SMMR 
a. $1979-99$ (15\% cut-off)

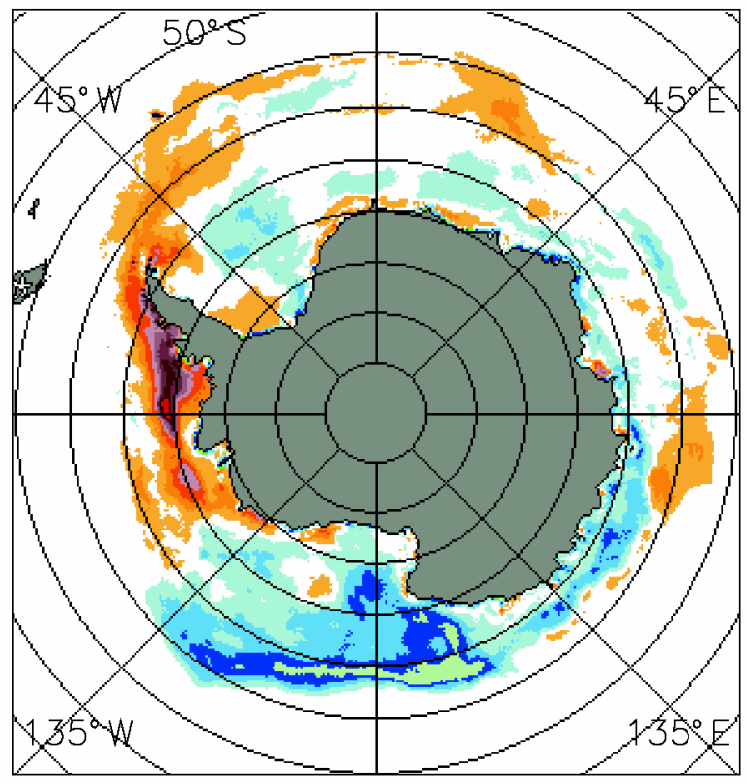

Trend (days/year)

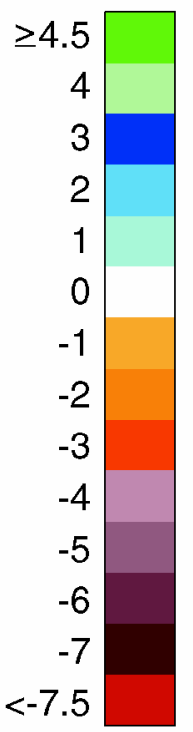

b. $1979-99$ (50\% cut-off)

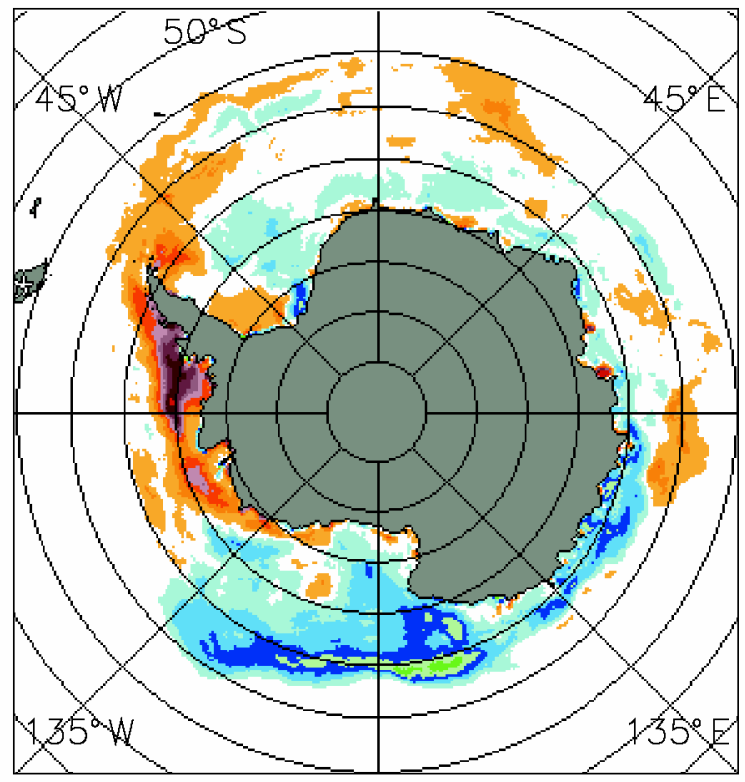

Fig. 3. Trends in the length of the sea-ice season over the 21 years 1979-99, using (a) a 15\% ice-concentration cut-off, and (b) a 50\% ice-concentration cut-off.

and SSM/I datasets are described in Cavalieri and others (1999). The ice concentrations have spatial resolutions of approximately $55 \mathrm{~km}$ and are gridded to a consistent grid with gridcell size approximately $25 \times 25 \mathrm{~km}$ (NSIDC, 1992).

The sea-ice concentration data are used here to determine the length of the sea-ice season in each year at each gridpoint, by counting the number of days with ice coverage of at least $15 \%$. Alternative ice-concentration cutoffs of $30 \%$ and $50 \%$ have also been used, with similar patterns resulting irrespective of which cut-off is selected (e.g. next section and Parkinson, 1994). The 15\% cut-off is used for the main results in this paper both because it is the standard cut-off used for the ice-extent results from the same dataset (e.g. Zwally and others, in press) and because comparison of the ice concentrations from the NASA Team algorithm with those derived from other algorithms yields a close match in distributions of ice coverage of at least $15 \%$ but some substantial differences in distributions of ice of higher concentrations (e.g. Comiso and others, 1997; Hanna, 1999; Markus and Cavalieri, 2000). The $15 \%$ results are thus considered the most robust.

The trend in the length of the sea-ice season is calculated at each ocean gridpoint as the slope of the line of linear least-squares fit through the 21 years of season-length data. The calculations are done through matrix manipulations on the 21 annual matrices of the length of the sea-ice season for the $15 \%$ ice-concentration cut-off, and are then repeated for the $30 \%$ and $50 \%$ cut-offs. For the trend calculations, each year's season lengths are linearly scaled to equivalents for a 365 day year.

In order to obtain a measure of statistical significance for the trend results, an estimated standard deviation $(\sigma)$ of the 21 year trend is calculated at each gridpoint following Taylor (1997). Trends are considered statistically significant when the trend magnitude exceeds $1.96 \sigma$, signifying a $95 \%$ confidence level that the slope is non-zero. Trends that additionally meet the criterion of exceeding $2.58 \sigma$ are considered statistically significant at a 99\% confidence level (Taylor, 1997).

\section{RESULTS}

\section{Season lengths}

Figure 2 presents maps of the length of the sea-ice season for the beginning and ending years of the dataset and for the 21 year average over the period 1979-99. All three sets of results are presented for an ice-concentration cut-off of $15 \%$, and the 21 year averages are also presented for an iceconcentration cut-off of $50 \%$. The 1979 and 1999 maps show both similarities, some of which are apparent in all the yearly maps, and some clear contrasts between the two years. Similarities include the existence of perennial ice (or, more precisely, ice coverage lasting at least 360 days of the year) in the far western Weddell Sea, the tendency for season lengths to decrease outward from the coast, and the anomalously short ice seasons in the southwestern Ross Sea compared to other locations of similarly high latitudes (Fig. $2 \mathrm{a}$ and b). Differences include the substantially greater area of perennial ice in the Amundsen Sea and especially the Bellingshausen Sea in 1979 than in 1999, contrasted by the substantially lesser area of perennial ice in the Ross Sea in 1979 than in 1999. Differences also include the prominent arm of long ice seasons extending northeastward in the western Weddell Sea in 1979 but not in 1999, and the much shorter ice seasons in the western Ross Sea in 1979 than in 1999 (Fig. 2a and b). The 21 year averages (Fig. 2c) indicate that for the latter phenomenon, the 1999 case was more typical than the 1979 case. Also, the prominent arm of long ice seasons in the western Weddell Sea in 1979 (Fig. 2a), which can be explained on the basis of the cyclonic gyre often apparent in the Weddell Sea (e.g. Gordon, 1978), does not appear in the 21 year averages (Fig. 2c), and in fact shows up prominently only in years 1979, 1980 and 1992, with less prominent appearances in 1984, 1991, 1996 and 1998 (visible in the individual yearly data, not shown here except for the years 1979 and 1999).

The 21 year averages are presented both for a $15 \%$ ice- 


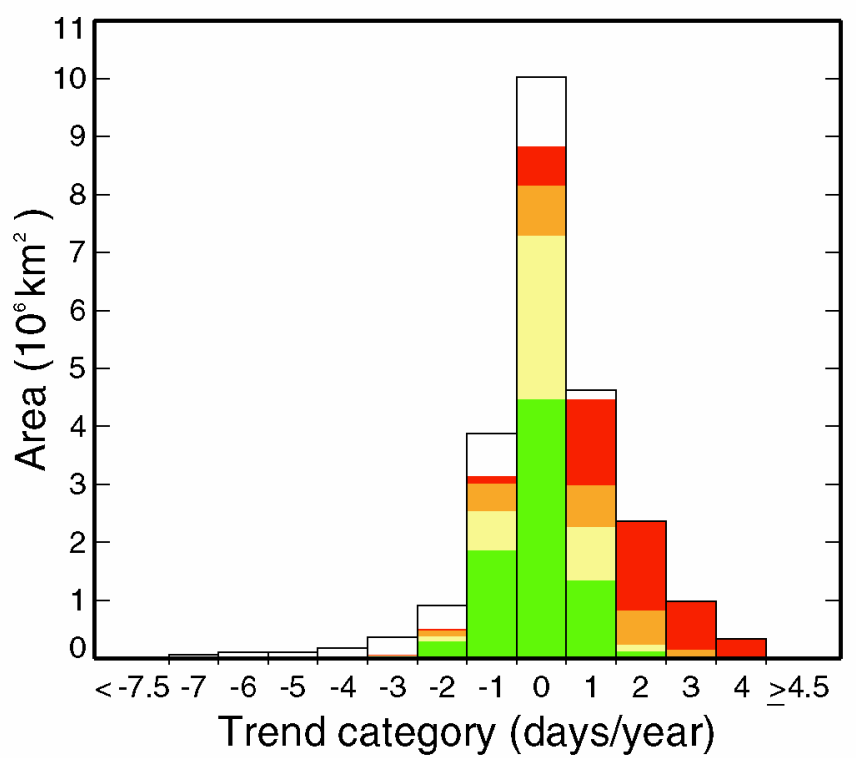

\begin{tabular}{|l}
$\square$ Bellingshausen/Amundsen Seas \\
$\square$ Ross Sea \\
$\square$ Western Pacific Ocean \\
$\square$ Indian Ocean \\
$\square$ Weddell Sea
\end{tabular}

Fig. 4. Histogram showing the area of the Southern Ocean seaice cover experiencing various levels of trends in the length of the sea-ice season over the 21 years 1979-99, with bar segmentation to identify the contributions from each of the five sectors of the Southern Ocean identified in Figure 1. The histogram corresponds to Figure 3a, i.e. using a 15\% ice-concentration cut-off and the same trend categories as in Figure 3. It compiles the results of all pixels having an average of at least 1 day of $\geq 15 \%$ sea-ice coverage per year over the 21 years. (Without the latter, or similar, restriction, the bar centered at 0 would peak far off the scale, as it would incorporate a considerable area equatorward of the sea-ice region.) concentration cut-off and for a 50\% ice-concentration cut-off to verify that the basic patterns remain the same irrespective of which cut-off is used (Fig. 2c and d). Naturally, with a stronger criterion for ice coverage, the $50 \%$ cut-off yields season lengths that are generally less and never more than those for the 15\% cut-off (Fig. 2c and d). For instance, immediately off the Ross Ice Shelf, all gridcells have at least 255 days with ice of concentration at least $15 \%$ (Fig. 2c), whereas some pixels have fewer than 195 days with ice of concentration at least 50\% (Fig. 2d). This is an extreme case, brought about by the polynyas (areas of open water within an ice pack) that commonly form immediately off the Ross Ice Shelf. Still, despite the few large numerical differences between the $15 \%$ and $50 \%$ cases, the spatial patterns are quite similar throughout the images (Fig. 2c and d).

\section{Trends}

Trends in the length of the sea-ice season over the 21 years are presented in Figure $3 \mathrm{a}$ for an ice-concentration cut-off of $15 \%$ and in Figure $3 \mathrm{~b}$ for an ice-concentration cut-off of $50 \%$. The marked similarity of these two images illustrates the robustness of the results with respect to the choice of the specific ice-concentration cut-off used. In spite of the fact that some locations have much shorter seasons with $\geq 50 \%$ ice coverage than with $\geq 15 \%$ ice coverage (Fig. $2 d$ vs Fig. 2c), either cut-off yields a very similar pattern of trends (Fig. $3 \mathrm{a}$ and b).

Linear least-squares trends for the 21 year period show an overall lengthening of the sea-ice season throughout most of the Ross Sea, around the coast of much of East Antarctica and in part of the south-central Weddell Sea (Fig. 3a). They show an overall shortening of the sea-ice season in almost the entire Bellingshausen Sea, most of the Amundsen Sea, the far westernWeddell Sea, the northwestern Weddell Sea, the northern portions of the ice pack at about $15-35^{\circ} \mathrm{E}$ and $85-110^{\circ} \mathrm{E}$, and a few small coastal areas between $25^{\circ} \mathrm{W}$ and $80^{\circ} \mathrm{E}$ (Fig. 3a). In general, the regions of positive and negative trends are fairly coherent and identifiable, with little speckling of the colors. The coherent trend patterns suggest a lack of randomness, reinforcing the interpretation that the trends reflect valid physical changes.

\section{a. $95 \%$ significance}

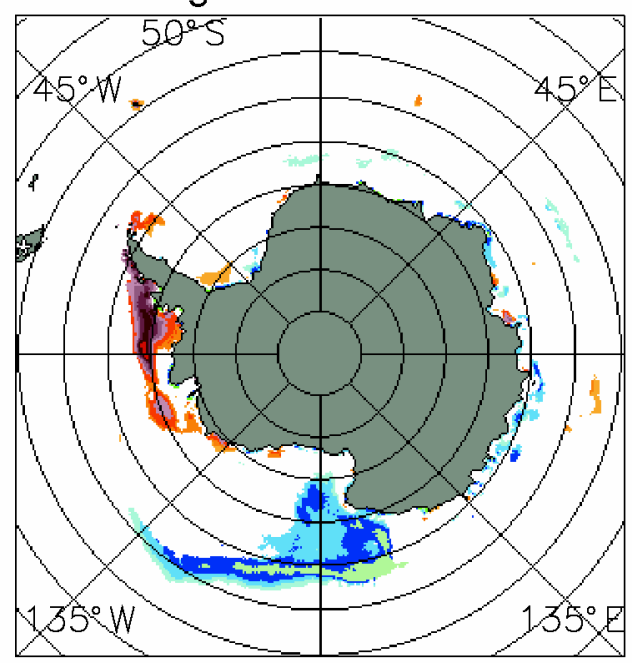

Trend (days/year)

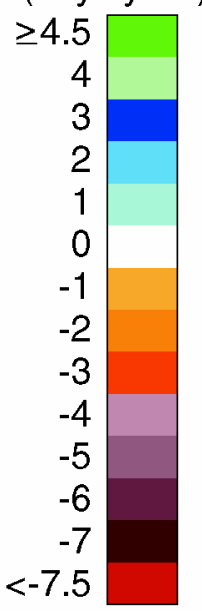

b. $99 \%$ significance

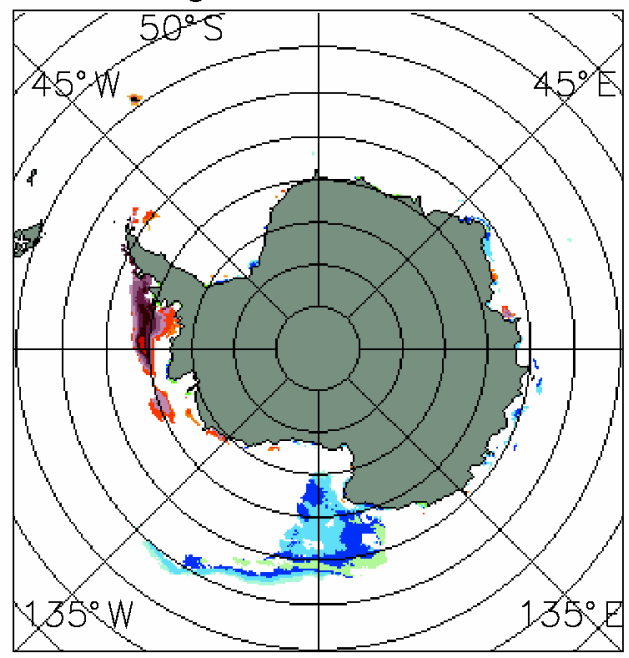

Fig. 5. Statistically significant trends in the length of the sea-ice season over the 21 years 1979-99, using a 15\% ice-concentration cut-off and zeroing out all trends that do not reach statistical confidence levels of $(a) \geq 95 \%$ or $(b) \geq 99 \%$. 
Although the strongest trends indicated in Figure 3 are negative trends within the Bellingshausen Sea, overall the area covered by positive trends exceeds that covered by negative trends. Specifically, for the case using a $15 \%$ iceconcentration cut-off (Fig. 3a), the area covered by positive trends of at least 0.5 days per year is $8.3 \times 10^{6} \mathrm{~km}^{2}$, whereas the area covered by negative trends of at least 0.5 days per year is $5.6 \times 10^{6} \mathrm{~km}^{2}$, making the area covered by positive trends of that magnitude $48 \%$ greater than that covered by negative trends (Fig. 4). The contrast is even stronger when considering trends of mag nitude at least 1.5 days per year, for which positive trends cover an area of $3.7 \times 10^{6} \mathrm{~km}^{2}$ and negative trends cover $1.7 \times 10^{6} \mathrm{~km}^{2}$, making the area covered by positive trends $114 \%$ greater (using area values to three decimal places, namely, $3.714 \times 10^{6} \mathrm{~km}^{2}$ and $1.737 \times 10^{6} \mathrm{~km}^{2}$, respectively) than the area covered by negative trends (Fig. 4). The positive trends greater than 1.5 days per year are predominantly from the Ross Sea region, while the negative trends greater than 1.5 days per year are predominantly from the Bellingshausen and Amundsen Seas and those greater than 2.5 days per year are overwhelmingly from the Bellingshausen and Amundsen Seas (Figs 3 and 4). For a wholenumber division, the area experiencing a least-squares-fit lengthening of the ice season of at least 1 day per year is $5.6 \times 10^{6} \mathrm{~km}^{2}$, while the area experiencing a least-squares-fit shortening of at least 1 day per year is $3.0 \times 10^{6} \mathrm{~km}^{2}$.

\section{Comparisons with earlier studies, reversals and confidence levels}

When examined for the 8 years 1979-86, the first 8 years of the 21 year dataset used here, the length of the sea-ice season was found to have shortened in the northern portions of the Bellingshausen and Amundsen Seas, the northern Weddell Sea, the eastern Weddell Sea and the near-coastal regions around East Antarctica (Parkinson, 1994; Watkins and Simmonds, 2000). Lengthening of the sea-ice season occurred throughout most of the Ross Sea, in the south-central Weddell Sea and around much of East Antarctica away from the nearcoastal region (Parkinson, 1994; Watkins and Simmonds, 2000). So for both the 8 year and the 21 year records, the ice season predominantly shortened in the Bellingshausen, Amundsen, and northwestern Weddell Seas, predominantly lengthened in the Ross Sea and south-central Weddell Sea and had a more mixed pattern around the rest of the continent. However, in the sizable areas where the signs of the trends match, the magnitudes tend to be larger in the shorter, 1979-86 record than in the 21 year record, reflecting rate decreases and/or reversals in the trends since 1986. Indeed, both Parkinson (1998) and Watkins and Simmonds (2000) note some reversals for the periods 1988-94 and 1989-96, respectively, vs 1979-86.

In view of the trend reversals, it is particularly important not to over-interpret the results of Figure 3. This figure gives a clear visualization of the overall changes in the length of the sea-ice season for the 21 year period 1979-99, but it incorporates fluctuations within the record, likely related to various oscillations within the climate system (e.g. Gloersen, 1995; White and Peterson, 1996), and its values should not be projected into the future. A reasonable further step with the season-length calculations would be to fit higher-order or harmonic curves to the data, especially if the selected formulation could be justified on theoretical or observational bases.
Despite the fluctuations over the 21 year period and the fact that linear least-squares fits are used for the calculation of season-length trends, some of the trends in Figure 3 do reach statistical significance. This is true of many of the trends calculated for locations in the Ross and Bellingshausen Seas, as well as some of the trends in the Amundsen Sea and at other locations scattered around the continent. Figure $5 \mathrm{a}$ shows those trends in Figure 3 a having statistical significance with a confidence level of $95 \%$ or above; and Figure $5 \mathrm{~b}$ shows the trends having statistical significance with a confidence level of $99 \%$ or above. The two largest intact regions with statistical significance center in the Bellingshausen Sea, where the trends are negative, and in the northern and northwestern Ross Sea, where the trends are positive. In both of these regions there are sizable areas where the significance is at the 99\% confidence level (Fig. 5b). Still, for most gridpoints within the Southern Ocean ice cover, the calculated trends are not statistically significant (Fig. 5a vs Fig. 3a).

\section{SUMMARY AND DISGUSSION}

Satellite passive-microwave data have been used to determine and map the length of the sea-ice season in each year 1979-99, with results showing (a) season leng ths generally decreasing outward from the coast except in regions of coastal polynyas, (b) perennial ice cover consistently in the far-western Weddell Sea and more selectively elsewhere around the continent, and (c) decidedly short ice seasons (for the high latitudes involved) off the Ross Ice Shelf (Fig. 2). Trends in the season lengths over the 1979-99 period show that: (a) most of the Ross Sea underwent a lengthening of the sea-ice season, (b) most of the Amundsen Sea and almost the entire Bellingshausen Sea underwent a shortening of the sea-ice season, (c) the Weddell Sea had a shortening of the sea-ice season in the northwest but a lengthening of the season in a substantial area of the south-central sea, and (d) around much of East Antarctica, the near-coastal region experienced a lengthening of the season, while further from the coast there was a more even mixture of areas experiencing season shortenings and those experiencing season lengthenings (Fig. 3). Integrating spatially, a much larger area of the Southern Ocean experienced an overall lengthening of the sea-ice season over the 2lyears 1979-99 than experienced a shortening (Fig. 4).

These results complement results on trends in the Southern Ocean ice extent (defined as the area having seaice concentrations of at least $15 \%$ ) found from the SMMR and SSM/I record. Analyses of the regional and hemispheric ice extents for the 16 year period 1979-94 by Stammerjohn and Smith (1997) and for the 20.2 year period from November 1978 through December 1998 by Zwally and others (in press) reveal positive ice-extent trends for the Weddell Sea, the Western Pacific Ocean, the Ross Sea and the Southern Ocean as a whole and negative ice-extent trends for the Bellingshausen and Amundsen Seas. The mapped results of the trends in the length of the sea-ice season (Fig. 3) provide a far more detailed spatial picture of the 21 year changes in the Southern Ocean than is possible when examining the ice extents, but at the same time, they provide a far less detailed temporal picture. Together, the ice-extent and season-length results show an overall increasing Southern Ocean ice cover, with the Bellingshausen and Amundsen Seas and the farwestern and northwestern Weddell Sea showing instead ice- 
cover decreases. These results are consistent with reports of notable warming over the Antarctic Peninsula from 1978 to 1996 (King and Harangozo, 1998; Skvarca and others, 1998; both studies also include years prior to 1978) and with a tendency for air-temperature anomalies in the peninsula region to be opposite in sign to those predominating over much of the rest of the Antarctic (Rogers, 1983; Stammerjohn and Smith, 1997).

The satellite-derived Southern Ocean sea-ice results, with overall lengthening sea-ice seasons (Figs 3 and 4) and increasing ice extents (Stammerjohn and Smith, 1997; Zwally and others, in press), provide a sharp contrast with the widely publicized overall ice-cover decreases in the Arctic occurring over the same period. Many uncertainties remain, but one certainty is that the ice covers of the two hemispheres have not been fluctuating synchronously over the past two decades.

\section{AGKNOWLEDGEMENTS}

I thank N. DiGirolamo and J. Eylander of Science Systems and Applications, Inc., for their much appreciated help in generating the figures; T. Scambos, V. Lytle and an anonymous reviewer for their very kind and helpful reviews of the text and figures; and the NASA Cryospheric Sciences and Earth Observing System programs for providing research funding. The sea-ice concentration datasets are available from the U.S. National Snow and Ice Data Center (NSIDC), Boulder, CO.

\section{REFERENGES}

Bentley, C. R. 1984. Some aspects of the cryosphere and its role in climatic change. In Hansen, J. E. and T. Takahashi, eds. Climate processes and climate sensitivity. Washington, DC, American Geophysical Union, 207-220. (Geophysical Monograph 29, Maurice Ewing Series 5.)

Cavalieri, D. J., C. L. Parkinson, P. Gloersen, J. C. Comiso and H. J. Zwally. 1999. Deriving long-term time series of sea ice cover from satellite passive-microwave multisensor data sets. f. Geophys. Res., 104(C7), $15,803-15,814$.

Comiso, J. C., D. J. Cavalieri, C. L. Parkinson and P. Gloersen. 1997. Passive microwave algorithms for sea ice concentration: a comparison of two techniques. Remote Sensing Environ., 60(3), 357-384.
Drewry, D. J., R. M. Laws and J. A. Pyle, eds. 1993. Antarctica and environmental change: Proceedings of a Royal Society discussion meeting held on 20 and 21 May 1992. Oxford, Clarendon Press for Royal Society.

Gloersen, P. 1995. Modulation of hemispheric sea-ice cover by ENSO events. Nature, 373(6514), 503-506.

Gloersen, P., W. J. Campbell, D. J. Cavalieri, J. C. Comiso, C. L. Parkinson and H. J. Zwally. 1992. Arctic and Antarctic sea ice, 1978-1987: satellite passivemicrowave observations and analysis. Washington, DC, National Aeronautics and Space Administration. (NASA SP-511.)

Gordon, A. L. 1978. Deep Antarctic convection west of Maud Rise. F. Phys. Oceanogr., 8(4), 600-612.

Hanna, E. 1999. Recent observations of Antarctic sea-ice. Weather, 54(3), 71-87.

King, J. C. and S. A. Harangozo. 1998. Climate change in the western Antarctic Peninsula since 1945: observations and possible causes. Ann. Glaciol., 27, 571-575.

Markus, T. and D. J. Cavalieri. 2000. An enhancement of the NASA Team sea ice algorithm. IEEE Trans. Geosci. Remote Sensing, GE-38(3), 1387-1398

Massom, R. A. 1988. The biological significance of open water within the sea ice covers of the polar regions. Endeavour, New Ser., 12 (1), 21-27.

National Snow and Ice Data Center (NSIDC). 1992. DMSP SSM/I brightness temperature and sea ice concentration grids for the polar regions on CD-ROM. Users' guide. Boulder, CO, National Snow and Ice Data Center. (Special Report 1.)

Parkinson, C. L. 1994. Spatial patterns in the leng th of the sea ice season in the Southern Ocean, 1979-1986. 7. Geophys. Res., 99(C8), 16,327-16,339.

Parkinson, C. L. 1998. Length of the sea ice season in the Southern Ocean, 1988-1994. In Jeffries, M. O., ed. Antarctic sea ice: physical processes, interactions and variability. Washington, DC, American Geophysical Union, 173-186. (Antarctic Research Series 74.)

Rogers, J. C. 1983. Spatial variability of Antarctic temperature anomalies and their association with the Southern Hemisphere atmospheric circulation. Ann. Assoc. Am. Geogr., 73(4), 502-518.

Skvarca, P., W. Rack, H. Rott andT. Ibarzábal y Donángelo. 1998. Evidence of recent climatic warming on the eastern Antarctic Peninsula. Ann. Glaciol., 27, 628-632.

Smith, R. C. and 10 others. 1995. The Palmer LTER: a long-term ecological research program at Palmer Station, Antarctica. Oceanography, 8(3), 77-86.

Stammerjohn, S. E. and R. C. Smith. 1997. Opposing Southern Ocean climate patterns as revealed by trends in regional sea ice coverage. Climatic Change, 37(4), 617-639.

Taylor, J. R. 1997. An introduction to error analysis: the study of uncertainties in physical measurements. Secondedition. Sausalito, CA, University Science Books.

Watkins, A. B. and I. Simmonds. 2000. Current trends in Antarctic sea ice: the 1990s impact on a short climatology. F. Climate, 13(24), 4441-4451.

White, W. B. and R. G. Peterson. 1996. An Antarctic circumpolar wave in surface pressure, wind, temperature and sea-ice extent. Nature, 380(6576), 699-702.

Worby, A. P., N. L. Bindoff, V. I. Lytle, I. Allison and R. A. Massom. 1996. Winter ocean/sea ice interactions studied in the East Antarctic. Eos, 77(46), 453,456-457.

Zwally, H. J., J. C. Comiso, C. L. Parkinson, D. J. Cavalieri and P. Gloersen. In press. Variability of Antarctic sea ice 1979-1998. 7. Geophys. Res. 